\title{
Photo- and redox-active host assemblies
}

\author{
C. Dennis Hall ${ }^{*}$, Gregory J. Kirkovits, Natasha K. Djedovic, Thi-Kim-Uyen Truong \\ and James R. H. Tucker ${ }^{\dagger}$
}

Department of Chemistry, King's College London, Strand, London WC2R 2LS, UK.

$\dagger$ Present address: Department of Chemistry, The University of Exeter, Stocker Road, Exeter, UK, EX4 $4 Q D$.

\begin{abstract}
The synthesis and characterisation of host assemblies containing photo- and/or redox active centres is described. Fluorescence spectra and cyclic voltammetry data on these materials are presented and their potential use as voltage-regulated optical switches or voltage-gated ion channels is discussed.
\end{abstract}

\section{VOLTAGE-REGULATED OPTICAL SWITCHES}

The synthesis, structure determination, electrochemistry and complex formation of cryptands containing metallocene units have been afforded considerable attention in recent years (ref. 1). The condensation of 1,1 '-ferrocene bis-acid chloride with diazamacrocycles, which normally produces a mixture of monomeric and dimeric cryptands containing amide functions (ref. 2) is a common synthetic route to these compounds. All the available $\mathrm{nmr}$ and $\mathrm{X}$-ray crystallographic data show that the amide functions are disposed trans to each other in the free ligand (refs. 3-5) but complex formation with a wide range of cations involves rotation of the amide carbonyl groups to cis orientations in order to coordinate the guest cation in conjunction with coordination by other heteroatoms within the macrocyclic structure (refs. 6, 7). Recent work involved the synthesis of analogous cryptands, 1-3, incorporating nitrogen donor atoms within phenanthroline or bipyridyl units and these also have the amide carbonyl groups disposed trans to each other (refs. 8-10). X-ray crystallography reveals that complexation with a cation (in this instance, $\mathrm{Na}^{+}$with 3) again involves coordination by carbonyl groups and heterocyclic atoms with two guest species encapsulated within the cryptand cavity (ref. 10). Compounds 1-3 were designed with the objective of complexing lanthanide cations in order to create redox-active luminescent cryptates analogous to the luminescent complexes originally described by Lehn (ref. 11). The additional feature of interest, however, is the ability to oxidise such a cryptate electrochemically which might then encourage dissociation of the luminescent guest by electrostatic repulsion. Extensive electrochemical studies on macrocycles and cryptands containing ferrocene units certainly support this contention (ref. 12ab). The host guest assembly therefore affords the basis of a voltage regulated optical switch and the work presented here describes further progress in this direction in terms of fluorescence associated with ligands, 1-3, their parent macrocycles 4-6 and the respective lanthanide complexes. Figures 1 and 2 show the luminescence associated with the $\mathrm{Eu}^{3+}$ complex of 5 and the $\mathrm{Tb}^{3+}$ complex of 6 respectively. Table 1 summarises the data obtained from all three parent macrocycles and shows clearly that the fluorescence is metal-centred since the emission spectra are dependent upon the lanthanide cation but not dependent on the host molecule. In several instances, however, the fluorescence is very weak and occasionally non-existent which suggests that the energy transfer is sometimes inefficient. Disappointingly, with cryptates derived from 1 and 2 the fluorescence disappeared completely and these findings may be ascribed either to coordination with carbonyl oxygen outside the cavity or to quenching by photo-induced electron transfer (PET) from the ferrocene units. With cryptand 3 complexation was evidenced by a slow change in $\lambda_{\max }$ of the uv absorption spectrum from $286 \mathrm{~nm}$ to $312 \mathrm{~nm}$. The change occurred over several hours after which excitation at $342 \mathrm{~nm}$ gave weak, metal-centred emission at 590 and $615 \mathrm{~nm}$. This may be due to slow formation of the encapsulated cryptate but may also be due to $\mathrm{Eu}^{3+}\left(\mathrm{H}_{2} \mathrm{O}\right)_{\mathrm{n}}$ - catalysed hydrolysis of the amide link to reform 6. Unfortunately, all three cryptands have so far resisted our efforts using a wide range of reducing agents to prepare the corresponding amine cryptands which would not be subject to hydrolysis. In the meantime model compounds 7-10 will be examined in an attempt to resolve the question of amide coordination or electron transfer as the source of fluorescence quenching.

* Lecture presented at the 1st International Conference on Supramolecular Science and Technology, Zakopane, Poland, 27 September-3 October 1998.

Other presentations are published in this issue, pp. 2337-2408. 
Table 1 Fluorescence data on ligands (1.2 mM) in $\mathrm{CH}_{2} \mathrm{Cl}_{2} / \mathrm{CH}_{3} \mathrm{CN}, \lambda_{\text {exc }}=320 \mathrm{~nm}$; $\left[24 \mathrm{mM} \mathrm{Ln}{ }^{3+}\right]$

\begin{tabular}{|c|c|c|c|}
\hline & \multicolumn{3}{|c|}{$\lambda_{\mathrm{F}}, \mathrm{nm}$ (Intensity) } \\
\hline Ligand & $\mathrm{Eu}^{3+}$ & $\mathrm{Dy}^{3+}$ & $\mathrm{Tb}^{3+}$ \\
\hline & $580(5)$ & - & $544(3)$ \\
\hline & $594(17)$ & - & $584(1)$ \\
\hline & $613(31)$ & - & $622(1)$ \\
\hline & & & \\
\hline
\end{tabular}

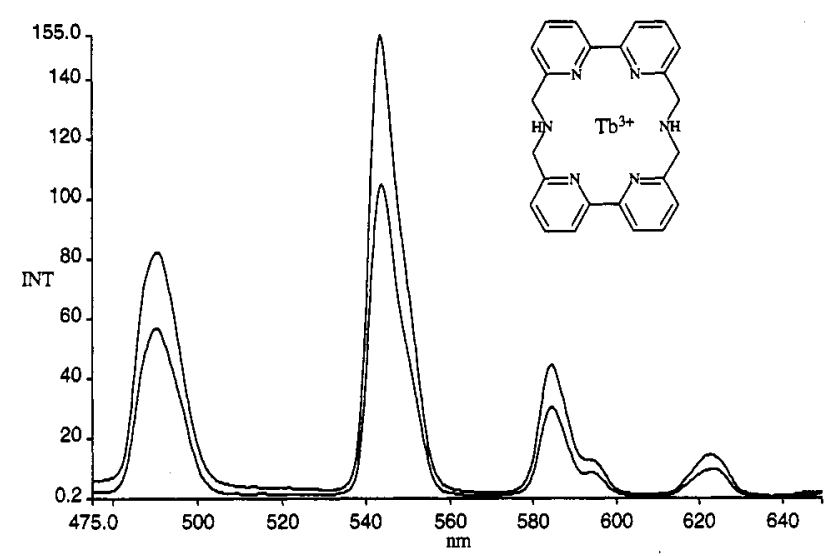

Figure $11.2 \mathrm{mM}$ solution in $\mathrm{CH}_{2} \mathrm{Cl}_{2}$ with 1 eq and $22.4 \mathrm{eq} \mathrm{Tb}^{3+}$ in $\mathrm{CH}_{3} \mathrm{CN}$

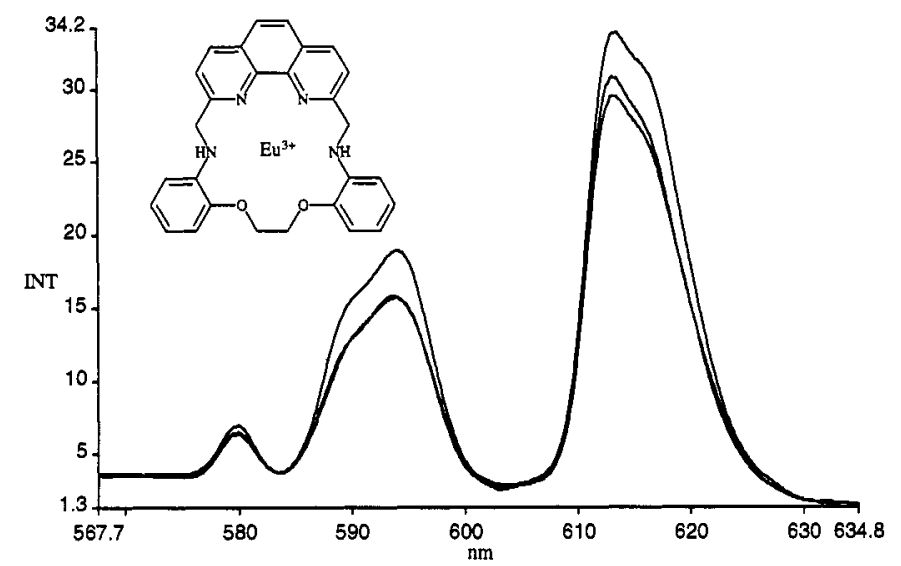

Figure $21.2 \mathrm{mM}$ solution in $\mathrm{CH}_{2} \mathrm{Cl}_{2}$ with 1 eq, 2 eq and $22.4 \mathrm{eq} \mathrm{Eu}^{3+}$ in $\mathrm{CH}_{3} \mathrm{CN}$ 

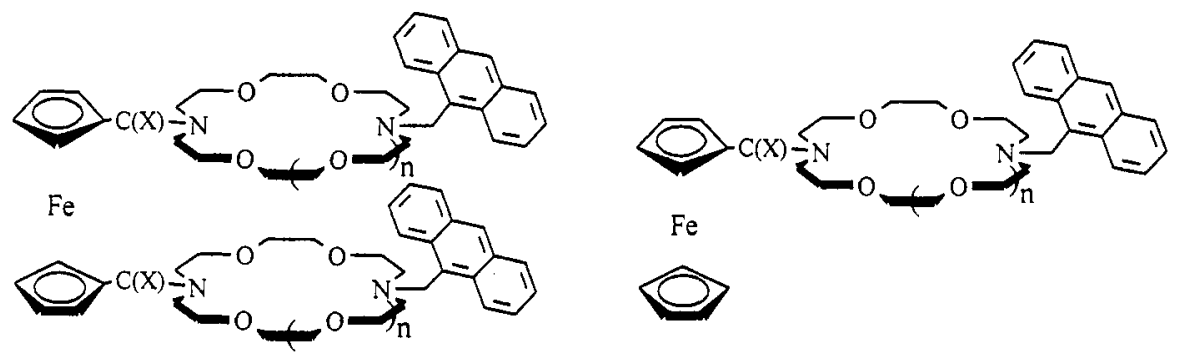

$\mathrm{Fe}$

(7) $x=0$

(9) $x=0$

(8) $\mathrm{X}=\mathrm{H}_{2}$

$\mathrm{n}=1,2$

(10) $X=H_{2}$<smiles>CC1(C)CCOCCOCCN2CCOCCOCCN1c1cccc3cc4ccccc4c-3c1C2</smiles>

(11ab) a, $n=1$

b, $n=2$

Scheme 1

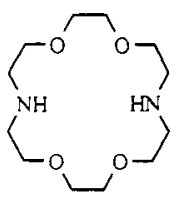

(i)
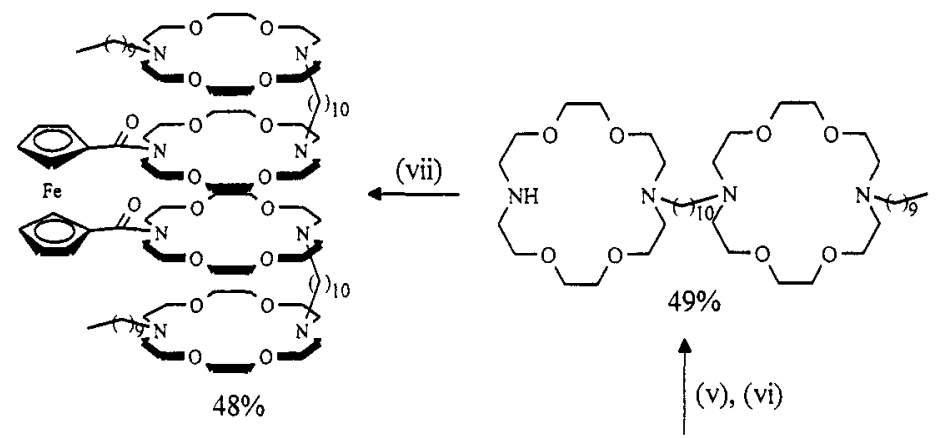

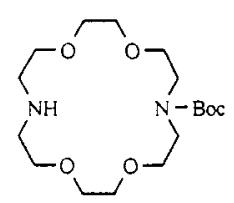

$35 \%$

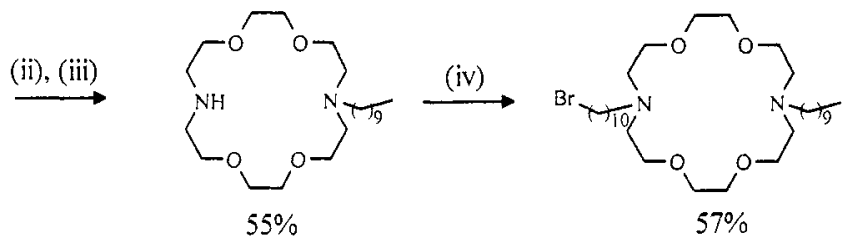

Reagents: i) $\mathrm{Boc}_{2} \mathrm{O}$, dioxan; ii) $\mathrm{CH}_{3}\left(\mathrm{CH}_{2}\right)_{9} \mathrm{Br} / \mathrm{Na}_{2} \mathrm{CO}_{3} / \mathrm{KI} / \mathrm{PrCN}$; iii) $\mathrm{CF}_{3} \mathrm{CO}_{2} \mathrm{H} / \mathrm{CH}_{2} \mathrm{Cl}_{2}$; iv) $\mathrm{Br}\left(\mathrm{CH}_{2}\right)_{10} \mathrm{Br} / \mathrm{Na}_{2} \mathrm{CO}_{3} / \mathrm{KJ} / \mathrm{PrCN}$; v) $\mathrm{N}$-Boc-diazacrown $/ \mathrm{Na}_{2} \mathrm{CO}_{3} / \mathrm{KJ} / \mathrm{PrCN}$;

vi) $\mathrm{CF}_{3} \mathrm{CO}_{2} \mathrm{H} / \mathrm{CH}_{2} \mathrm{Cl}_{2}$; vii) ferrocene $(\mathrm{COCl})_{2} / \mathrm{Et}_{3} \mathrm{~N} /$ toluene 


\section{VOLTAGE-GATED ARTIFICIAL ION CHANNELS}

Transport of certain ions through phospholipid membranes is required for energy metabolism, generation of signals in the nervous system and signal transduction processes (ref. 13). Ion conductance across membranes may take place by diffusion or by a channel mechanism where the host assembly creates a tunnel-like pathway for the guest (ref. 13). Most known channel formers involve protein aggregates containing helical trans-membrane segments but recently considerable efforts (e.g. ref. 14) have been made to synthesise ion channels capable of simulating the effect(s) of natural ion channels.

Our approach to this problem has been the design and construction of a channel containing a redoxactive unit (e.g. ferrocene) which, when oxidised, would inhibit ion-transport by charge repulsion effects (ref. 12). The strategy is shown in Scheme 1 and the synthesis of the first redox-active artificial ion channel is outlined in Scheme 2. The host assembly, obtained as a viscous orange oil, was characterised by mass spectrometry, i.r. and ${ }^{1} \mathrm{H} /{ }^{13} \mathrm{C} \mathrm{nmr}$. Electrochemical studies are in progress and utility as an ion channel is currently being explored by patch champ (electrophysiology) techniques.

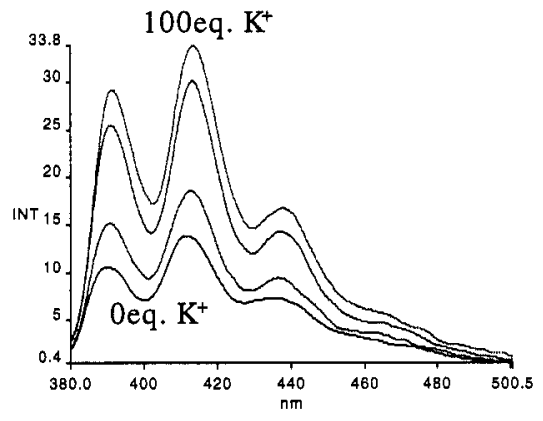

Figure 3. Fluorescence spectra of $11 \mathrm{~b}$ $\left(1 \times 10^{-5} \mathrm{M}\right)$ in $\mathrm{CH}_{3} \mathrm{CN}$ with increasing amounts of $\mathrm{K}^{+}, \lambda_{\text {ex. }}=363 \mathrm{~nm}$.

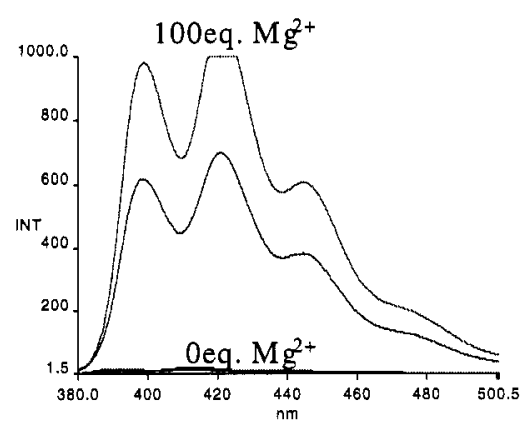

Figure 4. Fluorescence spectra of $11 \mathrm{~b}$ $\left(1 \times 10^{-5} \mathrm{M}\right)$ in $\mathrm{CH}_{3} \mathrm{CN}$ with increasing amounts of $\mathrm{Mg}^{2+} . \lambda_{\text {ex. }}=363 \mathrm{~nm}$.

In conjunction with this work, complex formation between azamacrocycles and biologically important cations $\left(\mathrm{Na}^{+}, \mathrm{K}^{+}, \mathrm{Mg}^{2+}\right.$ and $\left.\mathrm{Ca}^{2+}\right)$ is being studied by fluorescence techniques using model compounds (11ab). The fluorescence spectra for $(\mathbf{1 1 b})$ with $\mathrm{K}^{+}$and $\mathrm{Mg}^{2+}$ are shown in Fig. 3. As expected (ref. 15) the cations inhibit PET from the coordinating nitrogen atoms to the excited anthracene fluorophore and the intensity of the fluorescence is highly dependent upon the charge density of the complexed cation. Similar (though less spectacular) emission spectra were obtained with 11a and the results indicate that the macrocycles within the artificial channel do complex the relevant cations. This aspect of the work will develop further as the fluorescence spectra of compounds $\mathbf{7 - 1 1}$ are explored more thoroughly.

\section{ACKNOWLEDGEMENTS}

Thanks are due to the EPSRC, King's College London and Rhone-Poulenc (formerly RTZ Chemicals) for financial support to G.J.K., N.K.D., T.K.U.T. and J.H.R.T.

\section{REFERENCES}

1. a) P. D. Beer, Adv. Inorg. Chem., 79-110, 39, (1992).

b) D. Dietrich, P. Viout. J.-M. Lehn, Macrocyclic Chem., Chap. 3, VCH. Weinheim (1993).

c) J.-M. Lehn, Supramolecular Chem., Chap. 8, VCH, Weinheim (1995).

2. A. P. Bell, P. J. Hammond and C. D. Hall, J. Chem. Soc., Perkin Trans. 1, $707-715$ (1983).

3. P. D. Beer, J. Elliot, P. J. Hammond, C. Dudman and C. D. Hall, J. Organomet. Chem., 236, C37-C42 (1984).

4. P. D. Beer, C. D. Bush and J. A. Hamor, J. Organomet. Chem., 339, 133-138, (1988).

5. a) C. D. Hall, I. P. Danks, S. C. Nyburg, A. W. Parkins and N. W. Sharp, Organometallics, 9, 1602-1607, (1990). 
b) C. D. Hall, A. W. Parkins, S. C. Nyburg and N. W. Sharp, J. Organomet. Chem., 407, 107-113, (1991).

6. C. D. Hall, J. H. R. Tucker and N. W. Sharp, Organometallics, 10, 1727-1731, (1991).

7. a) C. D. Hall, J. H. R. Tucker, A. Sheridan, S. Y. F. Chu and D. J. Williams, J. Chem. Soc., Dalton, 3133-3136, (1992).

b) C. D. Hall, J. H. R. Tucker, S.Y.F. Chu, A.W. Parkins, and S.C. Nyburg, J. Chem. Soc., Chem. Commun., 1505-1507 (1993).

8. C. D. Hall and T.-K.-U. Truong, J. Organomet. Chem., 519, 185-194, (1996).

9. C. D. Hall, T.-K.-U. Truong and S. C. Nyburg, J. Organomet. Chem., 547, 281-286, (1997).

10. C. D. Hall, T.-K.-U. Truong, J. H. R. Tucker and J. W. Steed, J. Chem. Soc., Chem. Commun., 2195-2196, (1997).

11. B. Alpha, V. Balzani, J.-M. Lehn, S. Perathoner and N. Sabbatini, Angew Chem. Int. Ed. Engl., 1266-1267, (1987).

12. a) C. D. Hall, N. W. Sharp, I. P. Danks and Yu Pak Sang, J. Chem. Soc., Chem. Commun., 419-421 (1989)

b) C. D. Hall and S. Y. F. Chu, J. Organometallic Chem., 498, 221-228, (1995).

13. W.D. Stein, Channels, Carriers and Pumps, Academic press, New York (1990).

14. O. Murillo, I. Suzuki, E. Abel, C.L. Murray, E.S. Meadows, T. Jin and G.W. Gokel, J.Amer. Chem. Soc., 119, 5540-5549 (1997)

15. A. P. de Silva, H. Q. N. Gunaratne, T. Gunnlaugsson, A. J. M. Huxley, C. P. McCoy, J. J. Rudmacher and T. E. Rice, Chemical Reviews, 97, 1515-1566, (1997). 